\title{
PROCEEDINGS OF THE ASSOCIATION OF INDUSTRIAL MEDICAL OFFICERS
}

\section{FIFTY-THIRD MEETING}

The Fifty-Third (Annual General) Meeting of the Association was held at the London School of Hygiene and Tropical Medicine on Oct. 29 and 30, 1948. The President, Dr. A. J. Amor, was in the Chair, and seventytwo members attended.

In introducing the Report of the Council for the year 1947-48, Dr. Amor said that four meetings of the Association had been held, three in London and one in Glasgow. The Council had also held four meetings during the year. The outstanding event of the year had been the Ninth International Congress on Industrial Medicine, which had been well supported by members. The Council had replied to the Inter-Departmental Committee on the remuneration of Consultants and Specialists that Industrial Medicine must be regarded as a speciality. The first number of a Quarterly Bulletin had been published, to keep members acquainted with the activities of the Association. The President also reported that the library facilities of the London School of Hygiene and Tropical Medicine had now been made available to members, and it was agreed that Prof. J. M. Mackintosh should be thanked for this gesture. The sub-committee on the provision of medical services for small units had reported earlier in the year and the report was sent to the B.M.A. Occupational Health Committee. In conclusion, the President thanked all members for their whole-hearted co-operation in the working of a successful year.

The Hon. Treasurer, Dr. J. A. A. Mekelburg, then presented the Accounts, which were adopted without discussion. Some discussion then took place on a proposal to increase the annual subscription, but it was decided that the subscription should not be increased for the ensuing year. A proposal to amend the Constitution in relation to Membership was not proceeded with.

The following were elected Officers and Members of the Council for the year 1948-49: Hon. Secretary : Dr. J. A. A. Mekelburg ; Hon Treasurer : Dr. W. G. S. Pepper ; Hon. Editor of Transactions : Dr. L. Norman ; Council Members (Ordinary Members) : Drs. M. L Dobbie-Bateman, J. S. Spickett, H. F. Chard, W. Gunn, R. E. W. Fisher, L. J. Hayden, N. G. Marr, and S. B. Scott ; Council Member (Associate Member) : Dr. F. Wrigley.

The following were elected to represent the Groups on the Council: Birmingham: Dr. J. G. Billington; Yorkshire : Dr. R. A. Trevethick ; London : Dr. G. E. Graves-Peirce; Manchester : Dr. G. Taylor; Nottingham : Dr. J. Magill Young; Scottish : Dr. D. M. Watson; South Wales and West of England: Dr. G. Stenlake-Mundy ; and Tees-side : Dr. F. H. C. Beards.

On Saturday morning, Oct. 30, Mr. R. A. Hacking, of Messrs. Richard Thomas and Baldwin, addressed the Association on the subject of the manufacture of steel. Mr. Hacking described the properties of naturally occurring iron and gave an account of the extraction of iron, together with the chemical and physical factors involved in the various processes. The remarkable tenacity of iron for oxygen was shown by the fact that at $600^{\circ} \mathrm{C}$. an extremely low vacuum would be required to reduce the metal to the pure element, whereas some other metals, such as silver, could be reduced to the element by heating to this temperature. Chemical reducing processes were the basis of the production of iron, and carbon was used in the process for the production of pig iron, leading to the formation of cast iron, which was the metal run off the bottom of the furnace. Mr. Hacking went on to describe the Bessemer process, in which air is blown through the molten metal to produce steel, and the open-hearth process for the production of steel which was the method most extentively used in Britain today. Over 80 per cent. of steel was produced by the open-hearth process, about 8 per cent. by the Bessemer process, and 4 per cent. by the electric-arc process which was used for the production of high-class steels. Mr. Hacking showed a number of slides to illustrate the details of the various procedures, and went on to describe the geographical distribution of British steel works, which were centred around coalfields except for the one at Coaby. which had been founded in 1935. A section of a furnace capable of producing 600 tons of steel a day was illustrated and described, together with the layout of a dockside steel works in South Wales and that of the very large Hermann Goering plant. At pressures up to $10 \mathrm{lb}$. per square inch or more, American engineers had succeeded in producing up to 1,700 tons of steel a day from a single furnace ; by means of added oxygen it was theoretically - possible to increase this to as much as 3,000 tons daily. Mr. Hacking then showed a colour film which his firm had produced to illustrate the details of the various processes concerned in the production of steel. The President, in thanking Mr. Hacking for his most interesting address, said that it was also helpful for Members to see this outline of one of the major industries which would no doubt be one of those visited at the Annual Provincial Meeting in South Wales in 1949.

\section{BIRMINGHAM GROUP}

Chairman : Dr. W. Jeaffreson Lloyd, Guest, Keen, and Nettlefolds Ltd.

Hon. Secretary : Dr. J. G. Billington, General Electric Co. Ltd., Witton, Birmingham.

A Meeting was held on May 19, 1948, at which the Group discussed the whole question of convalescent homes and rest break and holiday schemes. The Chairman felt that it was not only the so-called working class who required a break, but managements as well. 
The first speaker was Mr. Hughes of the Birmingham Hospital Saturday Fund, who said that the Fund's Convalescent Homes were outside the new Insurance Schemes as no treatment was given, and that they were asking work people to continue their voluntary subscriptions to carry on the homes. (This scheme is now working quite well.) In order to be quite fair to applicants for admission, no person would in future be normally allowed to go to a convalescent home in two consecutive years. Medical Certificates for admission to the homes from industrial medical officers were not accepted, and it was necessary for the patient's own doctors to issue such certificates. The Hospital Saturday Fund sent an average of two hundred people a week to the homes.

Mr. D. M. Gibb (Warden) then spoke of the work done at Windmill House, Weatheroak, Alvechurch, Worcestershire. It was run by the Birmingham Association of Girls' and Mixed Clubs, and during the last five years they had taken some 20,000 people (mostly adolescents) of all kinds and with different backgrounds. The majority wanted to get away from the difficulties of home relationships. He tried to mix convalescents with club members and to accept everyone on the same basis, and also to make people feel they were individuals. The domestic duties were shared, and it was surprising how people talked of their troubles and how confidences were given over the washing-up. In fact, many friendships had been thus made. These troubles could not or would not be spoken of in people's own homes. Mr. Gibb concluded that he would be very pleased for anyone to visit Windmill House at any time, and he felt certain that visitors would not meet sad faces.

Dr. Lloyd spoke warmly of the value of such a home and gave instances of young workers from his factories who had benefited by their stay there and whose whole outlook had been improved.

An outline of convalescent and holiday schemes was then given. Dr. V. V. Brown of Messrs. Rubery Owen Ltd., spoke of the home owned by the firm, which was much appreciated by both men and women. Dr. Brown had the final task of selecting patients. The firm paid the railway fares and there were no charges to the workers. Dr. J. G. Lawson of Messrs. Joseph Lucas Ltd. said that for the past ten years his firm had had a home for women and girls at Weston-super-Mare. This was free to employees, who were selected by a Committee on recommendations by the foreman. Dr. C. H. Hoskyn of the Austin Motor Co. Ltd., said that their workers went to the Hospital Saturday Fund homes and that staff and work-people were helped by two schemes. Dr. J. G. Billington of G.E.C. Ltd. said that this was also so in his firm, who paid the fares to the convalescent homes. Dr. J. A. Duncan of I.C.I. (Metals) Ltd. said that his firm made an allowance for girls selected by the welfare officers. Return fares were paid by the firm.

Dr. J. B. Sherman of Cadbury Brothers Ltd. outlined his firm's comprehensive scheme. There was a men's remedial home at Harleck, owned by the firm, to which persons were sent on recommendation of foremen or shop committee members as being in need of a change either as a result of a strain at work, domestic trouble, or in order to avoid a period of absence from work. Board and travel were paid by the firm, who also gave allowances for children etc. where necessary. There were similar rest break houses for women, who were selected and helped in the same way. In addition the firm makes use of the Hospital Saturday Fund homes for convalescent cases.

Miss Frew (Almoner of the Birmingham United
Hospitals) advised all interested to obtain a copy of the Directory of Convalescent Homes issued by the King Edward Hospital Fund, London, at $5 s$. This guide gave the type of cases admitted and whether dressings were done or diets given.

On May 25, 1948, a visit was paid to the Aston Works of Messrs H.P. Sauce Ltd., where members were shown the processes for the making of vinegar, sauces, and pickles. The excellence of the raw materials, the steady improvement in the working conditions, with their emphasis on extreme cleanliness and absence of touch by hand, the efficient laboratory service, and the good "family spirit" shown in the works, were favourably commented upon.

The M.R.C. Unit of the Birmingham Accident Hospital were " at home" to the Group on June 21, 1948, when the Director, Dr. (now Professor) J. R. Squire, had prepared a programme dealing with the control of wound infection and with the problems of occupational dermatitis. There were many demonstrations, including photographs of industrial skin disease, tables showing the composition of normal skin fats, and an ingenious apparatus on the "Archimedean principle" which measured the increase in finger-tip volume in cases of suspected pulp infection. An increase in volume of 17 per cent. or over was an indication for immediate incision. Dr. G. N. Cruickshank showed the effect of various patent and other detergents on the removal of mineral oils from the skin, and showed by means of the ultra-violet lamp how the oil left in or on the skin after washing was readily visible as brilliant fluorescence. This test was convincing to the most sceptical and made us realize how tenacious mineral oils are, especially in the areas of skin where there are many hairs. Dr. G. Ricketts spoke about the natural fats of the skin surface and their relationship to self-sterilization. Dr. J. P. Bull spoke on the importance of minor injuries in causing lost time, and mentioned that Birmingham was especially a centre where fingers were so often injured and where any disability at all rendered the worker relatively useless, as so much of the city's industries demanded fine workmanship from supple fingers. He gave an account of the research work done by the M.R.C. Unit on " Experiments with occlusive dressings of a new plastic" later published (Lancet, 1948, 2, 213). The physical properties, in particular water-vapour permeability, of the nylon-derivative film suitable for wound dressings were described. The film is an effective barrier against micro-organisms, and tested on the human skin, the permeability of this film to water-vapour was shown to be sufficient to prevent the skin from becoming sodden. The bacterial flora of the healthy skin under the occlusive dressing became modified, Staph. aureus disappeared, and the variety of organisms was reduced. Clinical trials with the film were stated to be in progress and the preliminary results were promising.

Dr. E. Topley spoke of the work that she and Mr. S. H. Harrison had been doing on systemic penicillin in finger-pulp infection. The investigation was carefully controlled, one group receiving systemic penicillin, the other no general therapy. Staph. aureus sensitive to penicillin was isolated from over 90 per cent. of operation swabs. Systemic penicillin effectively reduced the incidence of positive swabs at subsequent dressings. Clinically the healing time was shorter in the penicillin series (average, controls 20.0, penicillin 14.7 days), and there was a lower complication rate. Operation was delayed in a series of patients on systemic penicillin. With delay fewer were incised, but the unsatisfactory 
results in the incised patients made this delay undesirable in routine treatment. Evidence was shown that local penicillin at operation and systemic penicillin for a complication are both much less effective than systemic penicillin started before operation. The average healing times improved throughout the investigation (for example, first months $35 \cdot 3$ days, last months $15 \cdot 6$ days). Evidence was given to suggest that one cause for the improvement was the use of a minimal incision in place of the classical hockey-stick incision.

On Nov. 9, 1948, Mr. Colin Johnston, who for the past three years has been conducting otological clinics in a number of large Birmingham factories gave a report of his work on infective ear disease. This paper has since been published (Brit. med. J., 1948, 2, 1049). Chronic ear diseases, in particular chronic suppurative otitis media, are potent causes of inefficiency and invalidism. A random selection of 1,902 employees showed 3.3 per cent. suffering with suppuration in the middle ear and 17.8 per cent. with active or healed middle-ear disease. A total of 1,711 patients complaining of ear, nose, or throat symptoms were examined at factory clinics ; 389 were found to suffer from disease of the pinna and external auditory meatus and 274 from C.S.O.M. Daily treatment after efficient diagnosis was essential, and of a hundred patients so treated thirtyeight might expect to have a dry ear after 5.2 weeks and to keep it dry for at leasf six months, 45 would have a dry ear but would relapse in less than six months, although standing a good chance with subsequent treatment, six would be rendered quiescent, and eleven would need a surgical operation. The results showed that conservative treatment would clear up infection in a high proportion of cases, but the prospects of obtaining a lifelong cure were poor. It was found that in manual workers productive efficiency was affected more by pain than by deafness, but that the latter might be a handicap to promotion. It was considered that the future expansion of otological treatment in factory medical departments was feasible and would reduce the present overloading of the hospital services.

\section{YORKSHIRE GROUP}

Chairman : Dr. S. A. Underwood,

Rowntree and Co. Ltd., The Cocoa Works, York.

Hon. Secretary : Dr. C. Cresdee, I.C.I. (Dyestuffs Division), Huddersfield.

A meeting of the Group was held at the Algernon Firth Institute of Pathology on Oct. 2, 1948. Drs. Underwood and Cresdee were elected Chairman and Hon. Secretary for the year 1948-49. Dr. Trevethick was elected Group Representative to the Council.

It was decided to change the name of the Group from the Leeds Group to the Yorkshire Group.

A discussion took place about methods necessary for stimulating the activities of the Group. It was realized that with a scattered membership it was difficult for members to attend ordinary meetings. The Chairman and Secretary thought the spreading of the places of meetings might help, and the Chairman suggested that four meetings should be held during the winter-two in Leeds, one in Sheffield, and one in York-and that the meetings should consist of a general discussion of the problems of members in relation to their own particular industry, and that one of the medical officers of the area in which the meeting was held should review his own particular industry and its problems.
A meeting was held in Sheffield on Saturday, Dec. 4, 1948. In the morning a tour was made of the Works of Steel, Perch, and Tozer. The Works Medical Officer, Dr. Trevethick, acted as guide. Instructive hours were spent in following the processes of manufacture from the first stages of the furnaces to the finished product of extruded steel and steel strips. The details of each section, the accompanying hazards, and the medical problems arising therefrom, were explained by Dr. Trevethick. During the past eleven months the steel output from this particular works reached the record of over three-quarters of a million tons. The tour ended with a visit to the medical department, where cases of skin grafting, burns, and other skin conditions were shown.

In the afternoon, twelve members were present at the ordinary meeting. Dr. Hartley, of Samuel Fox and Co. Ltd., addressed the meeting on the medical aspects of the steel industry. He pointed out that in many cases the buildings had been in use for some sixty to a hundred years, and conditions had remained the same except in modern works now being erected. On the credit side, however, there were extremely good labour relations. In his particular firm there had been no industrial dispute for a hundred years, and there had been no major upset in the steel industry for over forty years. The wages were high in comparison with many other industries. From the hazard point of view, accidents took first place, and as the medical service in the steel industry was still comparatively young a start was made by establishing an efficient accident service. The frequency rate of accidents was not disproportionately high, although the lighter side of the industry had many more minor accidents than the heavy side, where if an accident oceurred it was usually severe. In 1947 in his particular works there were five fatal accidents and five with a permanent partial disability. Dr. Hartley analysed the accident attendances over a period, and bruises, cuts, burns, and foreign bodies in the eye represented the major incidence. There were few toxic risks encountered, though the recent introduction of lead shot which had been incorporated into the steel was something to be watched very carefully. Dermatitis was generally due to oil and grease or to wear and tear. Investigation was beginning into the question of whether steel workers were prone to respiratory troubles or cancer. They worked in a very hot and dusty environment.

Dr. Trevethick then emphasized the fact that very extensive alteration to the present plant would be needed to improve local working conditions in the steel industry. In the early stages of his appointment as Works Medical Officer Dr. Trevethick had spent most of his time in becoming familiar with the works and getting to know the workers. The future would be along the lines of preventative medicine, and he instanced again the use of lead and other toxic materials that might be used in the manufacture of steel. So far, there had been no apparent ill effects. Dr. Trevethick mentioned the "wear and tear" dermatitis which was a very real problem and occurred after many years. The people in the spring-making department were exposed to multiple small burns. Heat stroke was another condition which had caused some anxiety, but it was now much reduced as a result of the provision of salt in tablet form, which the men preferred to saline drinks. Whereas, previous to the introduction of the sugar-coated saline tablets, workers complained that they were weary by evening, they now said they were less tired at the end of the working day. Sepsis was 
not an uncommon condition, and resulted from the many minor burns and scratches that were a hazard of the work.

Dr. Watson of Newton, Chambers and Co. Ltd., then addressed the members. His industry was mainly associated with iron foundries and chemical works. He demonstrated many interesting and practical methods of dealing with injured fingers and toes. He thought a good cosmetic result went with a good functional ability. Dr. Watson showed photographs and $x$ rays of injured digits.

A discussion followed, and Dr. Trevethick was thanked for the instructive day.

\section{SOUTH WALES AND WEST OF ENGLAND GROUP}

Chairman : Dr. J. S. Spickett, Richard Thomas and Baldwins Ltd., Bridgend, Glamorganshire.

Hon. Secretary : Dr. G. Stenlake-Mundy, The Bristol Aeroplane Company, Filton House, Bristol.

On Sept. 30, 1948, members of the Group visited the Royal Ordnance Factory at Pembrey. After an excellent lunch presided over by Mr. R. O. Bishop, Superintendent of the factory, a visit was made to the portion manufacturing ammonium nitrate. The plant devoted to the extraction of phosphorus from bombs and shells was also visited, and particular reference was made to precautions necessary for carrying out this work. The following departments were also included in the itinerary: the factory library, canteen and changing rooms, laundry, and boot repairing shop. The last three departments were really part of the extensive safety measures carried out in this factory, there being changing rooms, laundries for clothes, individual showers, baths, cubicles lined with white tiles, and drying rooms for damp clothes. Every worker was given each week a suit of special clothes; and special boots in certain parts of the factory.

A clinical meeting was held on Oct. 23, 1948, at the dermatological department of the Cardiff Royal Infirmary by kind invitation of Dr. Hodgson.

On Dec. 1, a visit was paid to the works of the Bristol Aeroplane Company Limited at Filton. Members visited the kitchens and dining halls. Bristol Wayfarers and Freighters were seen in course of construction. In the "press shop" special note was taken of the guarding of both large and small presses. The large Brabazon Hangars and the Brabazon I were inspected; then the various processes in the Rodney Works plating shop were seen and discussed. A foundry treating high-grade steel used in jet engines was seen, and also the engine test houses.

\section{TEES-SIDE GROUP}

Chairman : Dr. H. Fellows, Dorman Long and Co., Ltd., Middlesbrough.

Hon. Secretary : Dr. J. B. Adamson, Ministry of Fuel and Power, Newcastle-upon-Tyne.

A meeting was held at Durham on Nov. 10, 1948, when Prof. Alexander Kennedy of the Department of
Psychological Medicine, Royal Victoria Infirmary, Newcastle-upon-Tyne, spoke on psychological medicine and its relation to industry. He said it was essential for the works medical officer to have a general working knowledge of psychiatric methods, and towards this end teaching courses were to be established. Prof. Kennedy included observations on rehabilitation, compensation, and the organization of a mental health service in the region.

A meeting was held at Billingham on Dec. 15, 1948, when Dr. W. Gillies Annan, Medical Referee (Dermatologist) Durham County, and North Yorkshire, described the salient features and methods of treatment of fourteen different skin diseases.

\section{LONDON GROUP}

Chairman: Dr. G. E. Graves Peirce, Railway Executive, London Midland Region, Euston Station, London.

Hon. Secretary : Dr. R. E. W. Fisher, Chief Medical Officer,

South Metropolitan Gas Co., London.

A meeting of the London. Group was held at the London School of Hygiene and Tropical Medicine on Nov. 11, 1948. Dr. Graves Peirce was in the Chair and Mr. J. H. Simpson delivered an address on the deaf workman. Mr. Simpson dealt mainly with the problem of the workman who becomes deaf after he has taken up employment. He dealt with the various causes of deafness and explained how they could be prevented and also how early cases of deafness could be detected. After Mr. Simpson's address a representative of a commercial firm demonstrated an audiometer.

On Dec. 16, a meeting of the Group was held at Pimm's Restaurant. Mr. H. H. Kenshole read a paper entitled "Fringes of History," dealing with ailments of various historical personages and how they affected the course of history.

\section{SCOTTISH GROUP}

Chairman : Dr. D. Gordon Robertson, Imperial Chemical Industries Ltd., Nobel Division, Stevenston, Ayrshire.

Hon. Secretary : Dr. William Hunter, Wm. Collins Sons and Co. Ltd., Glasgow.

On April 14, 1948, the Scottish Group visited the Royal Infirmary, Glasgow, where Prof. L. J. Davies opened a discussion on hæmatology and industrial medicine.

During the week beginning June 14, the Scottish Group entertained the Association in Glasgow; the Proceedings of this meeting were reported in the January 1949 issue of the Journal.

A business meeting was held on Nov. 17, and an address was given by Dr. G. G. Browning, Consultant to the Ministry of Labour. Dr. Browning dealt with industrial rehabilitation from the aspect of the Ministry, and described in detail the facilities available for retraining, and the problems associated with this service. Considerable discussion followed.

On Dec. 11, the Group held a Social Meeting. 